\title{
Percepção sensorial de raízes de mandioca minimamente processada desenvolvida para agricultura familiar
}

A mandioca (Manihot esculena Crantz) é classificada como o sexto mais importante alimento em todo o globo, sendo consumida por mais de 800 milhões de famílias em todo o mundo. O objetivo deste estudo consiste em determinar as características sensoriais da mandioca de mesa minimamente processada produzida pelo Centro Tecnológico de Agricultura Familiar de Parauapebas (CETAF-Parauapebas), submetidas aos diferentes tratamentos para avaliar a qualidade e aceitabilidade dessa matéria-prima. Foram realizados os seguintes tratamentos: T1: raízes lavadas em água corrente; T2: raízes sanitizadas (150 ppm); T3: raízes sanitizadas ( 150 ppm) e acidificadas (1\% de ácido cítrico) e T4: raízes sanitizadas (150 ppm) e branqueadas (55ㄷ / 10 minutos). As raízes foram avaliadas sensorialmente quanto aos atributos aparência, textura, sabor e impressão global, utilizando-se da escala hedônica estruturada de nove pontos, sendo os extremos desgostei muitíssimo (1) e gostei muitíssimo (9). Para a intenção de compra, utilizou-se a escala estruturada de cinco pontos, cujos extremos foram: eu certamente compraria (1) e eu certamente não compraria (5). A partir destes resultados, observou-se que a mandioca minimamente processada é uma alternativa viável já que apresenta alta qualidade nutricional, organoléptica, frescor, aroma e sabor, assim como praticidade e economia de tempo no preparo diário, com elevada aceitação sensorial pelos potenciais consumidores.

Palavras-chave: CETAF-Parauapebas; Tratamentos; Qualidade; Aceitação.

\section{Sensorial perception of minimum processed cassava roots developed for family farming}

Cassava (Manihot esculena Crantz) is classified as the sixth most important food in the whole world, being consumed by more than 800 million families worldwide. The aim of this study is to determine the sensory characteristics of the minimally processed table cassava, produced by the Technological Center for Family Farming in Parauapebas (CETAF-Parauapebas), submitted to different treatments to assess the quality and acceptability of this raw material. The following treatments were carried out: T1: roots washed under running water; T2: roots sanitized (150 ppm); T3: roots sanitized (150 ppm) and acidified (1\% citric acid) and T4: roots sanitized $(150 \mathrm{ppm})$ and bleached (55ㅇ / 10 minutes). The roots were evaluated sensorially for the attribute's appearance, texture, flavor, and global impression, using the structured hedonic scale of nine points, the extremes being very disgusting (1) and very much enjoying (9). For the purchase intention, a structured five-point scale was used, the extremes of which were: I would certainly buy (1), and I certainly would not buy (5). From these results, it was observed that minimally processed cassava is a viable alternative since it presents high nutritional quality, organoleptic, freshness, aroma, and flavor, as well as practicality and time savings in daily preparation, with high sensory acceptance by potential consumers.

Keywords: CETAF-Parauapebas; Treatments; Quality; Acceptance.

Topic: Ciência de Alimentos

Reviewed anonymously in the process of blind peer.

Cleiton Moraes de Abreu

Universidade Federal Rural da Amazônia, Brasil http://lattes.cnpq.br/1599676355131339 dios-cleiton@hotmail.com

Maria Rebeca Araújo Castro (iD)

Universidade Federal Rural da Amazônia, Brasil http://lattes.cnpq.br/6562690215696388 http://orcid.org/0000-0001-7549-0209 mariarebeca323@gmail.com

Victória Carolline do Moraes Gatti (iD) Universidade Federal Rural da Amazônia, Brasil http://orcid.org/0000-0002-7400-1685 http://lattes.cnpq.br/5799448994510549 victoriagatti.agro@gmail.com
Received: 05/03/2020

Approved: 25/03/2020

\author{
Henrique da Silva Barata \\ Universidade Federal Rural da Amazônia, Brasil \\ http://lattes.cnpq.br/4298730265460752 \\ http://orcid.org/0000-0001-6356-4629 \\ henriquebarata2000@gmail.com \\ Fábio Israel Martins Carvalho (iD \\ Universidade Federal Rural da Amazônia, Brasil \\ http://lattes.cnpq.br/8221002637257793 \\ http://orcid.org/0000-0002-8995-2141 \\ fabioimc@yahoo.com.br \\ Priscilla Andrade Silva \\ Universidade Federal Rural da Amazônia, Brasil \\ http://lattes.cnpq.br/7666887041806711 \\ https://orcid.org/0000-0002-2774-3192 \\ prisciandra@yahoo.com.br
}

\section{Referencing this:}

ABREU, C. M.; CASTRO, M. R. A.; GATTI, V. C. M.; BARATA, H. S.; CARVALHO, F. I. M.; SILVA, P. A.. Percepção sensorial de raízes de mandioca minimamente processada desenvolvida para agricultura familiar. Natural Resources, v.11, n.2, p.1-6, 2021. DOI: http://doi.org/10.6008/CBPC2237-9290.2021.001.0001 


\section{INTRODUÇÃO}

A mandioca (Manihot esculenta Crantz), espécie originária do Brasil, pertencente à classe das dicotiledôneas, possui raízes tuberosas ricas em fécula, pertencente à família Euphorbiaceae, gênero Manihot composto basicamente por 98 espécies. Está distribuída principalmente nos continentes, americano, africano e asiático. No Brasil, possui importância socioeconômica bem definida, pois a grande quantidade de amido das suas raízes garante a segurança alimentar das famílias de baixo poder aquisitivo, devido sua versatilidade de uso, além de proporcionar renda aos pequenos agricultores que abastecem o mercado local de sua região (VIEIRA et al., 2013).

O sistema radicular da mandioca é composto por raízes fibrosas e raízes tuberosas (LI et al., 2010). As primeiras possuem a função de absorver água e sais, como também servirem de suporte de sustentação. Além disso, algumas dessas raízes através do processo de divisão celular e diferenciação de células dão origem às raízes tuberosas. Essas por sua vez, são responsáveis pelo acumulo de substâncias de reserva, principalmente o amido. Dessa forma, essas raízes agregam valor nutricional, pois combinam altos níveis de energia com vitaminas, minerais e fibra dietética, porém possuem baixo teor de proteínas em sua composição, entre $1 \%$ a $2 \%$ (Ll et al., 2010).

De acordo com a Organização das Nações Unidas para a Alimentação e a Agricultura (FAO, 2013), a mandiocultura é realizada principalmente por pequenos agricultores em mais de 100 países nos trópicos. Por ter raízes ricas em carboidratos e folhas com até $25 \%$ de proteína bruta, tornou-se por tanto, grande fonte calórica tanto na alimentação humana como animal. Segundo Aguiar et al. (2013), a fécula é um dos principais componentes nutricionais desta planta, podendo ser utilizada na indústria alimentícia, de produtos fármacos, bem como, para fabricação de madeira compensada e bioetanol, aponta a organização. A fécula é matéria-prima para o surgimento de diversos produtos como chocolate, leite em pó, embutidos, balas, biscoitos, embalagens, entre outros, podendo ser utilizada para esses fins na forma fermentada, modificada ou "in natura" (AGUIAR et al., 2013).

De acordo com Fernandes et al. (2017), a mandioca é considerada um alimento completo para os animais justamente pela interação entre carboidratos e proteínas. Suas raízes possuem entre 30\% e 35\% de energia, podendo assim, serem adicionadas nas formulações de rações, bem como fornecidas aos animais na forma "in natura", desidratadas e picadas na forma de ensilagem. A parte aérea é altamente proteica, apresenta entre $22 \%$ e $28 \%$ de proteína bruta e é considerada aproveitável nutricionalmente a partir do fornecimento da parte aérea fresca, desidratada e/ou picada em pedações de $1 \mathrm{~cm}$ a $2 \mathrm{~cm}$ diretamente no silo (FERNANDES et al., 2017). A parte aérea é uma importante fonte de alimento para ruminantes, embora possua quantidade de glicosídeos cianogênicos superior às raízes mesmo nas variedades mansas, podem ser picadas e secadas lentamente para serem fornecidas como silagem e feno (VALLE, 2007).

O objetivo deste estudo foi elaborar e caracterizar sensorialmente as raízes de mandioca minimamente processada, cultivada pelo Centro Tecnológico de Agricultura Familiar do município de Parauapebas (PA). 


\section{METODOLOGIA}

As diferentes formulações de mandiocas minimamente processadas foram desenvolvidos na Universidade Federal Rural da Amazônia no Campus de Parauapebas Pará, localizada nas coordenadas geodésicas $49^{\circ} 51^{\prime} 19^{\prime \prime}$ W latitude, $06^{\circ} 12^{\prime} 58^{\prime \prime}$ S longitude, com altitude de $197 \mathrm{~m}$ (com auxílio do GPS portátil, Modelo e Trex 10, Marca Garmin), assim como a análise sensorial. O período de realização do trabalho foi de outubro a dezembro de 2018. Para as formulações de mandioca adequadas, foram realizados vários testes com diferentes concentrações de cada matéria prima empregada.

Foram realizados os seguintes tratamentos: T1: raízes lavadas em água corrente; T2: raízes sanitizadas (150 ppm); T3: raízes sanitizadas (150ppm) e acidificadas (1\% de ácido cítrico) e T4: raízes sanitizadas (150 ppm) e branqueadas (55ㄷ / 10 minutos).

Nas diferentes formulações de mandioca minimamente processadas (T1, T2, T3 e T4), as raízes foram inicialmente lavadas em água corrente com auxílio de uma escova para remoção das sujidades (partículas de solo), em seguida realizou-se o descascamento manual das mesmas, bem como a retirada das pontas, posteriormente foram aplicados os cortes com aproximadamente 10 centímetros de comprimento, seguido de imersão em água fria $\left(5^{\circ} \mathrm{C}\right)$ (finalização do pré-tratamento para o T1). Para os tratamentos T2, T3 e T4, seguiram-se as referidas etapas: sanitização das raízes (150 ppm / 10 minutos), enxágue com água clorada (50 ppm / 10 minutos), drenagem com peneiras e leve secagem com papel toalha (finalização do pré-tratamento para o T2). Apenas para o tratamento T3 houve a imersão das raízes em uma solução de $1 \%$ de ácido cítrico por 24 horas. Já o tratamento T4, após enxágue com água clorada a 50 ppm e drenagem, supracitados, realizou-se o branqueamento das raízes através da imersão das mesmas em água a $55^{\circ} \mathrm{C}$ por 10 minutos.

A avaliação sensorial foi realizada na Universidade Federal Rural da Amazônia no Campus de Parauapebas, no mês de dezembro de 2018, por 100 provadores não treinados, selecionados aleatoriamente, de ambos os sexos, com faixa etária de 10 a 60 anos, pertencentes à comunidade acadêmica da UFRA. Foi solicitado avaliar cada amostra, individualmente, quanto à aparência, textura, sabor e impressão global (modo geral do produto), utilizando uma ficha de avaliação (Anexo B) com uma escala hedônica de nove pontos, ancorados em seus extremos nos termos: gostei muitíssimo (9) e desgostei muitíssimo (1) (ABNT, 1993; ABNT, 1998; STONE et al.; 1993). Quanto ao teste de intenção de compra, a fim de verificar se o produto seria bem comercializado ou não, com uma escala hedônica de 5 pontos, de acordo com o método de Dutcosky (2007).

\section{RESULTADOS E DISCUSSÃO}

As amostras de mandioca foram submetidas ao teste de aceitação sensorial por 100 provadores não treinados, as características sensoriais, podem ser observadas na Tabela 1. Observa-se na Tabela 1 que houve diferença significativa $(p<0,05)$ para os atributos sensoriais aparência e textura, apenas para o tratamento T3. Este resultado se deve ao fato de que os outros tratamentos aos quais não se realizou a adição de ácido cítrico, apresentaram muita semelhança nesses atributos citados. Já para o atributo sabor, 
verificou-se diferença significativa $(p<0,05)$ para os tratamentos $T 1$ e $T 3$, para o tratamento T1 isso ocorreu devido a não utilização de hipoclorito de sódio no tratamento. Em relação ao T3, verificou-se que o ácido deixou a massa ácida, o que gerou desconforto nos provadores e consequentemente, menor média observada para este tratamento nesse quesito.

Tabela 1: Avaliação sensorial da mandioca minimamente processada.

\begin{tabular}{lllll}
\hline & \multicolumn{3}{l}{ Atributos (média \pm desvio padrão) } & Impressão Global \\
\cline { 2 - 5 } Tratamentos & Aparência & Textura & Sabor & $7,96 \pm 0,80^{\mathrm{a}}$ \\
\hline T1 & $7,87 \pm 0,91^{\mathrm{a}}$ & $8,10 \pm 0,86^{\mathrm{a}}$ & $8,24 \pm 0,73^{\mathrm{a}}$ & $7,55 \pm 0,78^{\mathrm{ab}}$ \\
T2 & $7,52 \pm 0,88^{\mathrm{a}}$ & $7,65 \pm 0,88^{\mathrm{a}}$ & $7,75 \pm 0,80^{\mathrm{b}}$ & $3,67 \pm 0,84^{\mathrm{c}}$ \\
T3 & $4,71 \pm 0,99^{\mathrm{b}}$ & $4,37 \pm 0,80^{\mathrm{b}}$ & $3,76 \pm 0,91^{\mathrm{c}}$ & $7,50 \pm 0,85^{\mathrm{b}}$ \\
T4 & $7,78 \pm 0,94^{\mathrm{a}}$ & $7,79 \pm 0,89^{\mathrm{a}}$ & $7,60 \pm 0,96^{\mathrm{b}}$ & 0,4248 \\
\hline DMS & 0,4845 & 0,4463 & 0,4436 & $300,21^{\text {ns }}$ \\
\hline F calc. & $131,24^{\text {ns }}$ & $206,63^{\text {ns }}$ & $292,88^{n s}$ & 12,2990 \\
\hline CV & 13,4115 & 12,3391 & 12,5155 & .
\end{tabular}

T1 - Raízes apenas lavadas e descascadas / T2 - Raízes com adição do cloro / T3 - Raízes com adição de ácido cítrico / T4 - Raízes branqueadas. Os valores representam a média \pm desvio padrão de 100 provadores.

No tocante ao tratamento T1 do presente estudo, foram observados valores médios das notas atribuídas pelos provadores na faixa de 7,87 a 8,24, o que corresponde na escala hedônica "gostei moderadamente e "gostei muito" (Tabela 1)". Bezerra et al. (2010) obtiveram de 36 julgadores valores próximos de notas $(6,42$ a 7,22), ao avaliarem sensorialmente variedades de mandiocas de mesa com raízes de cores diversas. A maior nota $(7,87)$ atribuída pelos julgadores para o atributo aparência foi para o tratamento (T1) (Tabela 1). Esse valor está próximo da nota $(8,0)$ destinada para o mesmo atributo para Rinaldi et al. (2015) em analise sensorial de mandioca minimamente processada, armazenada e congelada em diferentes temperaturas.

Teixeira (2009) destaca que a avaliação da aparência é importante, pois é o primeiro contato do consumidor com o produto, no qual normalmente o consumidor procura produtos relacionados com a sua forma natural ou que seja consagrada culturalmente. Portanto, é fator determinante na aceitação ou rejeição do produto. Nesse contexto, infere-se que a maior nota ao tratamento T1 deve ter acontecido por não ter sofrido influência do hipoclorito, ácido cítrico e nem do branqueamento, estando assim, mais próximo da sua forma natural.

Para o atributo textura, destacam-se os tratamentos T1 $(8,10)$ e T3 $(4,37)$ (Tabela 1$)$, o que representa na escala hedônica "gostei muito" e "desgostei ligeiramente", respectivamente. Rinaldi et al. (2015) constataram para a textura valor médio $(7,80)$ de nota próxima ao averiguado no presente trabalho em relação aos tratamentos T1, T2 e T4 (Tabela 1). Sugere-se com esses resultados que o padrão preferido de mandioca cozida é aquele que mais se aproxima de um produto não farinácio, mas sim úmido, liso e macio, sensações degustativas que não foram verificadas no tratamento T3.

Segundo Teixeira (2009) o atributo textura é importante, pois determina para o consumidor como está a granulometria, aspereza, resistência, coesividade, crocância e a fibrosidade do alimento.

Quanto ao comportamento para o atributo sabor, pode-se observar que o tratamento T3 $(3,76)$ apresentou menor nota atribuída pelos provadores, quando comparado com os outros tratamentos do estudo (Tabela 1). Entende-se que o sabor ácido acentuado do ácido cítrico, sobressaiu e deixou a polpa 
com gosto desagradável. Segundo a Food Ingredients Brasil (2016) o ácido cítrico possui diversas aplicações na indústria de alimentos, sendo aplicado para reduzir $\mathrm{pH}$, controlar o crescimento microbiano, prevenir a turbidez do produto e entre outros. Contudo, essa substância neutraliza o sabor doce do alimento, podendo dessa forma deixar o produto com "gosto" de limão.

Os tratamentos T1, T2 e T4 receberam para o sabor, valores de notas atribuídas de 8,24, 7,75 e 7,60, respectivamente (Tabela 1), o que corresponde na escala hedônica a "gostei muito" e "gostei moderadamente". Valores semelhantes ao do presente estudo são relatados por Carvalho et al. (2011) em análise sensorial de mandioca cozida minimante processada sem adição de ácido cítrico, onde observaram o intervalo entre 7,67 e 8,39. Tal fato indica que o processamento da mandioca com utilização do hipoclorito de sódio e branqueamento, é capaz de manter o sabor do alimento próximo da raiz "in natura".

Tabela 2: Índice de aceitação das raízes de mandioca com base no atributo impressão global.

\begin{tabular}{|l|l|}
\hline Tratamentos & Índice de aceitabilidade (\%) \\
\hline T1 & 88,49 \\
\hline T2 & 83,93 \\
\hline T3 & 73,39 \\
\hline T4 & 83,04 \\
\hline
\end{tabular}

T1 - Raízes apenas lavadas e descascadas / T2 - Raízes com adição do cloro / T3 - Raízes com adição de ácido cítrico / T4 - Raízes branqueadas. Os valores representam o índice de aceitação calculado com base na nota atribuída pelos 100 provadores.

Com relação ao índice de aceitabilidade (IA) das raízes de mandioca minimamente processadas, foi observado no referido trabalho percentuais de 88,49 (T1), 83,93 (T2), 73,39 (T3) e 83,04\% (T4). Para Dutcosky (2011) os produtos para serem bem aceitos no mercado consumidor, precisam ter um índice de aceitação acima de 80\%. Logo, observa-se que o tratamento (T3) seria reprovado pelo mercado.

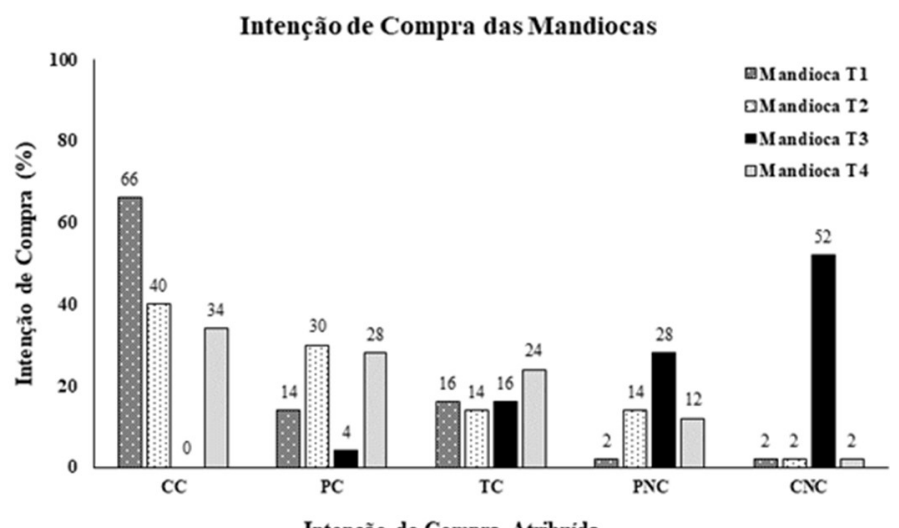

Figura 1: Intenção de compra para as raízes de mandioca. ${ }^{1}$

Para o teste de intenção de compra das raízes, observou-se na Figura 1, que 80 (T1), 70 (T2) e 62 (T4) dos provadores assinalaram que "certamente" ou "possivelmente" comprariam o produto se o encontrassem no mercado (Figura 1). O que reforça a boa aceitação das raízes de mandioca. Sanches (2017) obteve valores próximos de intenção de compra, de $85 \%$, na análise sensorial e viabilidade econômica de mandioca de mesa congelada e in natura. De acordo com o autor citado, a opinião dos

1 (T1 - Raízes apenas lavadas e descascadas / T2 - Raízes com adição do cloro / T3 - Raízes com adição de ácido cítrico / T4 - Raízes branqueadas). CC (Certamente Compraria), PC (Possivelmente Compraria), TC (Talvez Compraria), PNC (Possivelmente Não Compraria) e CNC (Certamente Não Compraria). 
consumidores possui grande relevância, uma vez que é importante verificar se o produto atende aos desejos e as necessidades dos consumidores.

Observa-se ainda, através da Figura 1, que para o tratamento 3, $80 \%$ de intenção de compra dos provadores, confirmaram que "possivelmente" ou "certamente" não comprariam o produto se o encontrassem à venda.

\section{CONCLUSÃO}

As partir da aplicação da análise sensorial, as raízes de mandioca minimamente processada, revelaram ser bem aceitas, com elevada aceitação global. Realizar o estudo sensorial desses produtos obtidos é fundamental para seus usos na indústria de alimentos como na alimentação humana.

Desse modo, evidencia-se que a mandioca minimamente processada é uma alternativa viável já que apresenta alta qualidade nutricional, organoléptica, frescor, aroma e sabor, assim como praticidade e economia de tempo no preparo diário, conquistando a preferência do consumidor. Além disso, pode ser melhor aproveitada pelo Centro Tecnológico Familiar de Parauapebas, como uma possibilidade de incentivar os agricultores familiares do Sudeste Paraense, a fortalecerem suas produções e assim intensificarem a venda desse produto na região.

\section{REFERÊNCIAS}

ABNT. Análise sensorial dos alimentos e bebidas: terminologia. São Paulo: ABNT, 1993.

ABNT. Escalas utilizadas em análise sensorial de alimentos e bebidas. São Paulo: ABNT, 1998.

AGUIAR, J. L. P.; SOUSA, T. C. R.; LÔBO, C. F.. Mandioca no cerrado: orientações técnicas (a importância da mandioca). Embrapa, 2013

BEZERRA, V. S.; FERREIRA, L. A. M.; PEREIRA, S. S. C.. Avaliação sensorial de variedades de mandioca de mesa com raízes de cores diversas. In: JORNADA NACIONAL DA AGROINDÚSTRIA, 4. Anais. Bananeiras, 2010.

CARVALHO, A. V.; SECCADIO, L. L.; SOUZA, T. C. L.; FERREIRA T. F.; ABREU, L. F.. Avaliação Físico-Química e Sensorial de Mandioca Pré-Processada Armazenada Sob Congelamento. Boletim do Ceppa, v.29, n.2, p.223-228, 2011.

DUTCOSKY, S. D.. Análise Sensorial de Alimentos. 2 ed. Curitiba: Champagnat, 2007

FAO. Mandioca: produzir mais com menos. FAO, 2013

FERNANDES, C. L. G.. Análises gráficas dos principais produtos agropecuários do estado do Pará: cultura da mandioca. Embrapa Amazônia Oriental, 2017.

FIALHO, F. J.; ANDRADE, R. F. R.; VIEIRA, A. E.. Mandioca no cerrado: questões práticas. Embrapa, 2013.

FIB. Ácidos Alimentícios. Revista Fi, n.37, p.29-42, 2016.
LI, K.; ZHU, W.; ZENG, K.; ZHANG, Z.; YE, J.; OU, W.; REHMAN, S.; HEUER, B.; CHEN, S.. Caracterização proteômica de embriões somáticos de mandioca (Manihot esculenta Crantz ), plântulas e raízes tuberosas. Proteome Science, v.27, 2010.

RINALDI, M. M.; VIEIRA, A. E.; FIALHO, F. J.; MALAQUIAS, V. J.. Efeitos de Diferentes Formas de Congelamento Sobre Raízes de Mandioca. Brazilian Journal Food and Technology, v.18, n.2, p.93-101, 2015

SANCHES, G. A.; SILVA, B. M.; MOREIRA, S. G. E.; COSME, S. S.. Análise Sensorial e Viabilidade Econômica da Mandioca de Mesa in natura e Congelada. Revista Brasileira de Tecnologia Agroindustrial, v.11, n.2, p.2332-2349, 2017.

STONE, H. S.; SIDEL, J. L.. Sensory Evaluation Practies. 2 ed San Diego: Academic Press, 1993.

VALLE, L. T.. Mandioca de mesa, macaxeira ou aipim: a hortaliça negligenciada pelo Brasil. Instituto agronômico (IAC), 2007

VIEIRA, A. E.; FIALHO, F. J.; SILVA, S. M.. Mandioca no cerrado: orientações técnicas (recursos genéticos e melhoramento da mandioca). Embrapa, 2013.

TEIXEIRA, V. L.. Análise sensorial na indústria de alimentos. Revista do Instituto de Lacticínios Cândido Tostes, v.64, n.366, p.12-21, 2009.

A CBPC - Companhia Brasileira de Produção Científica (CNPJ: 11.221.422/0001-03) detém os direitos materiais desta publicação. Os direitos referem-se à publicação do trabalho em qualquer parte do mundo, incluindo os direitos às renovaç̃oses, expansões e disseminações da contribuição, bem como outros direitos subsidiários. Todos os trabalhos publicados eletronicamente poderão posteriormente ser publicados em coletâneas impressas sob coordenação da Sustenere Publishing, da Companhia Brasileira de Produção Científica e seus parceiros autorizados. Os (as) autores (as) preservam os direitos autorais, mas não têm permissão para a publicação da contribuição em outro meio, impresso ou digital, em português ou em tradução. 